\title{
АРХЕОЛОГИЯ СОНОРЫ: ДРЕВНИЕ КУЛЬТУРЫ СЕВЕРНОЙ МЕКСИКИ И ИХ РОЛЬ В СТАНОВЛЕНИИ СВЯЗЕЙ МЕСОАМЕРИКИ И АМЕРИКАНСКОГО ЮГО-ЗАПАДА
}

Исследователям культур доколониальной Мексики хорошо известны месоамериканские цивилизации майя, ацтеков, ольмеков и др. Однако на северных окраинах древней Мексики развивались традиции, которые были связаны, как с миром индейцев Юго-Запада (США), так и Месоамерикой. Работа посвящена изучению древних культур северо-западной Мексики на примере археологии штата Сонора с учетом исследований ученых Мексики и США. В ней констатируется незначительное влияние элементов культуры Месоамерики (ранние формы традиционного земледелия, распространение украшений из меди, керамика), взаимодействие с культурами Юго-Запада (Касас Грандес, Хохокам), анализируется материальная культура (собирательство, земледелие, рыболовство), археологические объекты и предметы (строительство террас, ранее жилище, каменные орудия, изделия и украшения из морских раковин и др.).

Доказательства начала присутствия человека на территории современного штата Сонора датируются около 10000 г. до н.э. Первые обитатели этих мест были кочевыми охотниками и собирателями, которые использовали каменные орудия и орудия из ракушечника. Самые древние из них, общие для Соноры и Аризоны - это различные наконечники, хорошо известные археологам и определяемые как кловис. Они связаны с деятельностью охотников на мамонтов и других ископаемых животных и хронологически относятся к 9500-9000 г.г. до н.э.

На территории Соноры сформировались две основные культуры, связанные с особенностями географической среды. На засушливом побережье Калифорнийского залива жили охотники, рыболовы, собиратели морепродуктов. Они использовали моллюсков в качестве традиционной пищи, а также обменивали раковины, ракушки на прекрасную керамику, медные бубенчики и т.п. из Аризоны и Чихуахуа. Жители побережья также развивали древнюю навигацию.

На востоке Соноры в горных районах дождей выпадает больше. В этих местах создавались условия для заимствования месоамериканского типа земледелия с 1500 г. до н.э. (выращивание маиса, фрасоли, тыквы). Для данной территории характерно строительство каменных террас. Показателем появления постоянных поселений и формирования земледелия является керамика. Остатки керамикиздесьдатируются сер. VII-XIIIвB. В период XI - сер. XIV в. появляются комплексы небольших поселений с развитыми для данной эпохи торговыми (обменными) связями.

Традиции Соноры были связаны с культурами Чихуахуа (Касас Грандес), Аризоны (Хохокам), Синалои. Особое значение в распространении влияния Месоамерики имели древние культуры штата Синалоа (роль посредника).

В работе анализируются памятники петроглифики как проявление культуры аборигенов Соноры.

Ключевые слова: древняя северо-западная Мексика, археология штата Сонора, влияние Месоамерики, культуры Юго-Запада, материальная культура, археологические объекты и предметы.

\section{ARCHAEOLOGY OF SONORA: ANCIENT CULTURES OF NORTHERN MEXICO AND THEIR ROLE IN ESTABLISHING TIES BETWEEN MESOAMERICA AND THE AMERICAN SOUTHWEST}

Researchers of pre-colonial Mexico cultures are familiar with Mesoamerican Mayan civilization, the Aztecs, the Olmecs, etc. However, on the Northern outskirts of ancient Mexico developed traditions that were associated with the world of Indians of the South-West (USA) and Mesoamerica. The article studies ancient cultures of northwestern Mexico by the example of archaeology of the state of Sonora, taking into account the research of Mexico and US scientists. It claims the insignificant influence of elements related to Mesoamerica culture (early forms of traditional farming, the spread of copper ornaments, 
ceramics), interaction with the cultures of the SouthWest (Casas Grandes, Hohokam), material culture (gathering, farming, fishing), archaeological sites and objects (construction of terraces, formerly dwelling, stone tools, products and ornaments from seashells, etc.).

There is evidence that human presence on the territory of the modern Sonora dates back as far as $10000 \mathrm{BC}$. The first inhabitants of this area were nomadic hunters and gatherers who used stone tools made of limestone. The most ancient of these, common to Sonora and Arizona, are the various arrowheads well known to archaeologists and defined as clovis. They are associated with the activities of mammoth hunters and other fossil animals and chronologically refer to 9500-9000 BC

Two main cultures associated with the peculiarities of the geographical environment formed on the territory of Sonora. The hunters, fishermen and seafood collectors lived on the dry coast of the Gulf of California. They used shellfish as a traditional food, and traded shells, seashells on beautiful pottery, copper bells, etc. from Arizona and Chihuahua. The inhabitants of the coast also developed ancient navigation.

Исследователям культур доколониальной Мексики хорошо известны месоамериканские цивилизации майя, ацтеков, ольмеков и др. Однако на северных окраинах древней Мексики развивались культуры, которые можно рассматривать как переходные, то есть, связанные как с миром индейцев Юго-Запада, так и Месоамерики. Эти культуры, их признаки и черты не проявляются так ярко, как в историко-культурных регионах Месмоамерики, однако их присутствие в доколониальной истории очевидно. Одним из таких северных регионов Мексики, где развивались указанные культуры, является штат Сонора.

Доевропейская история Соноры является сложной, а ее территория в течение тысячелетий была ареной для развития культур, которые отличались своеобразием. Их изучение имеет огромное значение для того, чтобы, как указывалось, понять историческое развитие Северо-Запада Мексики и Юго-Запада США, многообразие и своеобразие культурных форм, особенности образа жизни местных поселенцев в доиспанский период ${ }^{1}$.

\footnotetext{
${ }^{1}$ Имеется два основных варианта объяснения происхождения топонима Сонора. Согласно первому, группа испанских конкситадоров во главе с Алдьваром Нуньесом Кабеса де Вакой (Álvar Núñez Cabeza de Vaca) (вторая половина XVI в.) пробираясь к своей базе в Мексике после кораблекрушения, несла с собой образ Богоматери Скорбящей (Nuestra Señora de las Angustias) на
}

Rains are more common in the mountainous areas of the East of Sonora. In these places, there were conditions to borrow Mesoamerican type of agriculture from $1500 \mathrm{BC}$ (cultivation of maize, beans, pumpkin). This area is characterized by the construction of stone terraces. Ceramics is an indicator of the emergence of permanent settlements and the formation of agriculture. Remains of pottery date bvack to the middle VII-XIII centuries. In the period of XI mid. XIV complexes of small settlements with developed for that era trade (exchange) relations were constructed.

Traditions of Sonora were associated with the cultures of Chihuahua (Casas Grandes), Arizona (the Hohokam), Sinaloa. Of particular importance in the spread of the influence of Mesoamerica were ancient cultures of Sinaloa (the role of mediator).

The article analyzes the monuments of petroglyphics as a manifestation of the culture of Sonora natives.

Key words: ancient northwestern Mexico, Sonora archaeology, influence of Mesoamerica, southwestern culture, material culture, archaeological sites and objects.

Трагической датой для культур Соноры является период 1845-1853 гг., когда к США отошла треть территории Мексики. Как следствие, произошел разрыв индейских территорий, которые когда-то представляли собой единое целое, как в этническом, так и культурном отношении. В результате появились современные этнокультурные и географические единицы Юго-Запад (США) и Северо-Запад Мексики, которые когда-то были тем самым единым целым. Особенно это касается территории мексиканских штатов Сонора и Чихуахуа и североамериканской Аризоны.

Один из мексиканских чиновников, министр образования, ученыйХосе Васконселосв 1925 г. выразился в этом отношении весьма выразительно: «На станции Дон заканчивается цивилизация и начинается жареное мясо» (Дон это станция на ветке железной дороги между штатами Сонора и Синалоа) [4]. Сам того не ведая, автор этих слов фрактически определил то, что по представлениям того времени разделяло Мексику высоких древних цивилизаций

холсте. По пути они встретили индейцев опата. Индейцы называли Богоматерь «Сенора» или «Сонора» (при устной передаче такое искажение является обычным). Второй вариант объяснения названия связан с испанским словом «sonoro», которое переводится как «звонкий», «гулкий»: очевидно оно относилось к завыванию ветров, проносящихся над открытыми степными и пустынными пространствами Соноры. 
и племенные общества ее северных и северо-западных областей. Но, как увидим далее, благодаря современным археологическим исследованиям культурная картина доиспанской эпохи не является столь однозначной.

Засушливая территория Соноры в течение долгого времени не вызывала интереса у исследователей, занятых высокими культурами центральной и южной Мексики. В наши дни возможности, а также объем проводимых археологических исследований позволяют выяснить истинное место, занимаемое культурами Соноры в общей истории Мексики.

В Соноре выделяется две географических и культурных области, важных для исследования региональных доколониальных культур. На западе - это низменная, исключительно засушливая зона, которая ограничивается Калифорнийским заливом, а на востоке включает гористый район, где дождей, напротив, выпадает больше. Но в целом, Сонора и ее североамериканский двойник, штат Аризона (в смысле культурных и исторических связей) занимают наиболее засушливые территории: здесь выпадает осадков менее 400 мм в год, что является недостаточным для успешного развития земледелия. Правда, на восток от Соноры простирается горный район (Западная Сиерра Мадре), где влажность достаточная. Примечательно в этом отношении весьма точное и традиционное определение местоположения Соноры - между морем и пустыней.

Как известно, обстоятельства географической среды очень важны для развития культур в наши дни, тем более это касается древности. Поэтому в том числе на примере Соноры можно проследить влияние этого фактора на историю данного региона в доколониальный период.

Как указывалось, горные районы больше получали влаги, поэтому здесь сложились более сложные культуры, основанные на земледелии. Это, прежде всего, культура Касас Грандес (Пакиме) на территории современного мексиканского штата Чихуахуа. Она является первой земледельческой культурой, возникшей здесь под влиянием Месоамерики. Культура сформировалась в горных районах Чихуаухуа около 2100 г. до н.э. В пределах этого же времени ее черты проявились в Аризоне, а оттуда в Соноре, правда, много времени спустя (начиная с 1500 г. до н.э.) как отражение и составная часть процесса передвижения на юг этнических групп юто-науа. Удивительно, что земледелие возникло сначала в более отдаленной северной Аризоне, а не южнее, в Соноре. Кстати, по крайней мере, в XVI в. торговцы-менялы предпочитали двигаться вдоль горных районов, а не по низменным, болотистым частям соседней Соноры. И проникновение земледелия, среди прочего, осуществлялось посредством именно этого пути.

Что касается засушливой зоны, то здесь идентифицированы следы древних поселений, так называемой, культуры Хохокам (хохокам). В частности, это раннеземледельческое поселение Снейктаун в Аризоне. В Аризоне поселенцы доколониального периода строили большие ирригационные каналы. Для сравнения, в смежной с ней Соноре, такие инженерные сооружения пока не встречаются, по крайней мере до настоящего времени в отношении их отсутствуют доказательства достаточной степени убедительности ${ }^{1}$ [1; 2; 7].

Низменные районы на западе Соноры выходят к морю, поэтому первые поселенцы, появившиеся здесь, в дальнейшем использовали рыбу и морские продукты в целом как пищевые ресурсы. Кроме того, раковины являлись сырьем, из которого делали колющие и режущие детали орудий труда и оружия, украшения и т.п. Со временем обитатели побережья Соноры использовали их при обмене с соседними группами в Хохокам (Аризона) и особенно, обитателями Касас Грандес (Чихуахуа). Прежде всего, это касалось их главного поселения, Пакиме, куда раковины тоннами поступали с побережья. Наконец, близость к морю со временем позволила также развивать древнюю, первичную навигацию, которая хорошо известна по общеисторическим источникам применительно к проживающему здесь народу сери(с).

В целом, традиции Соноры хотя культурно и связаны с Чихуахуа и Аризоной, но имеют большое сходство с соответствующим в штате Синалоа. Дело в том, что именно культуры штата Синалоа считаются наиболее важным здесь, поскольку представляются символом, свидетельством влияния Месоамерики, пусть и незначительного на северные и северо-западные районы Мексики. Теоретически такое соседство позволяло Соноре приобретать новые знания и материалы через обмен с более южными, собственно месоамериканскими культурами юга, опять же, через территорию штата Синалоа.

Кроме использования собственно земледелия, в этом засушливом регионе создатели культуры хохокам отличаются тем, что построили внушительную систему ирригационных, оросительных каналов, практиковали ритуальную игру в мяч (пелота), но не имели бюрократического аппарата и могущественных властителей. 
Как конкретно проходил процесс формирования культур Соноры, каковы собственно эти культуры, открытые и исследованные на настоящий момент?

Известно, что заселение континента проходило из Азии через Берингов пролив. Первоначальные арктические охотники (и их потомки) со временем стали проникать вглубь американского континента. Доказательства начала присутствия человека на территории современного штата Сонора датируются около 10000 г. до н.э. Наиболее известные места, где найдены доказательства процесса первичного освоения территории Соноры - это археологический комплекс Сан Диегито в пустыне Эль Пинакате. Первые обитатели этих мест были кочевыми охотниками и собирателями, которые использовали каменные орудия и орудия из ракушечника. Самые древние из них, общие для Соноры и Аризоны - это различные наконечники, хорошо известные археологам и определяемые как кловис. Они связаны с деятельностью охотников на мамонтов и других ископаемых животных и хронологически относятся к 9500-9000 г.г. до н.э. В течение большей части этого периода климатические условия были более благоприятными, чем ныне, и территорию покрывала густая и разнообразная растительность.

Пример культуры Соноры данного времени - Эль Фин дель Мундо. Ее расположение и археологические компоненты делают это место уникальным для изучения трансформации среды, выживания первых поселенцев, региональной интеграции и взаимосвязей между этническими группами и ролью человека в процессе вымирания животных периода плейстоцена.

Археологический объект, зона Эль Фин дель Мундо был обнаружен в 2007 г. Часть этой археологической зоны - лагерь охотников. Речь идет о первом месте охоты на стадо мегафауны эпохи плейстоцена; правда, аналогичный объект в Мексике уже был открыт еще в 1957 г. Согласно данным исследований, обосновавшиеся здесь носители культуры кловис, охотились на американских мастодонтов и других животных эпохи плейстоцена. Их ископаемые останки (в частности, в виде костей мамонтов) были обнаружены в трясине. Находки показывают, что охотники делали из кварца наконечники и другие предметы [8].

В следующий период происходило медленное, но неуклонное развитие обществ охотников и собирателей. На протяжении длительного времени, как и в других местах северо-западной Мексики, этот исторический отрезок характеризуется использованием поселенцами камня в качестве основного приспособления для размельчения зерен и материала для изготовления наконечников и других колющих и режущих приспособлений. Данный этап разделяется на несколько фаз, которые получили свои названия от топонимов мест обнаружения артефактов в Аризоне того же периода. Эта эпоха имела принципиальное значение для развития, поскольку к ее окончанию формируется традиция возделывания культурных растений и начало строительства постоянных поселений.

Около IV в. до н.э. - II в. н.э. начинает проявляться традиция земледелия, определенная исследователями как Ранний земледельческий период. В Соноре эпоха Раннего земледельческого периода совпадает с продвижением сюда, на юг, начиная с 1500 г. до н.э. носителей языка юто-науа (юто-ацтека). Земледелие проникло из Месоамерики в соседнюю Чихуахуа и на юг Аризоны еще раньше. Речь идет о маисе (кукуруза) и тыкве, а также фрасоли и хлопке, которые появились здесь, по меньшей мере, около 2100 г. до н.э. Затем появилась и ирригация, хронологически определенная как 1200 г. до н.э.

Таким образом, земледелие не пришло в Сонору непосредственно из Месоамерики, а соседней, более северной Аризоны. Важно напомнить, что земледелие в Аризоне было более успешным, чем в Соноре из-за развития упомянутой ирригационной системы. Она представляла собой систему каналов, подающих речную воду на поля. Но таких каналов, как указывалось выше, не было на территории древней Соноры.

Известно, показателем появления постоянных поселений и, следовательно, формирования земледелия является керамика. Остатки керамики здесь датируются сер. VII-XIII вB. В период XI - сер. XIVв. в регионе фриксируется появление комплекса небольших поселений с достаточно развитыми для данной эпохи торговыми (обменными) связями.

Однако в низменных районах побережья Калифрорнийского залива земледелие не отмечено, поскольку здешние поселенцы, как указывалось, занимались рыболовством и сбором моллюсков. Болотистое, поросшее растительностью пространство побережья Калифорнийского залива позволяло заниматься рыболовством и особенно, сбором моллюсков всех видов. Они служили не только пищей, но 
также были бесценным материалом, которым жители этого региона Соноры могли обмениваться со своими соседями из Касас Грандес, Хохокам и группой небольших поселений на реке Гила и ее притоков. Одно из мест на реке Алтар, притоке реки Консепсион (задокументированное археологами под названием F.2.2Atil) превратилось в настоящий «коммерческий центр», где выходцы из Соноры обменивали свои раковины, ракушки, выловленные в Калифорнийском заливе, на прекрасную керамику, происходящую из Аризоны и Чихуахуа (рис. 1).
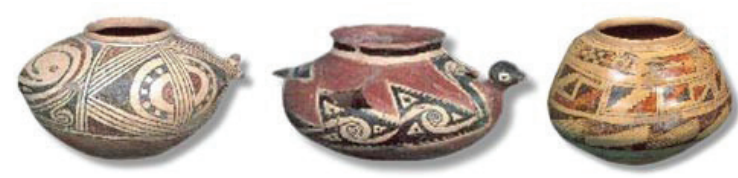

Рис. 1. Типичная керамика в системе обмена северо-западной Мексики

Это также изящные медные бубенчики, которые они получали, в частности, через культуру Касас Грандес, а также Снейктаун культуры Хохокам. Из этих мест в Соноре и получали разнообразные маленькие диски из сланца, декорированные мозаикой, браслеты из бирюзы, раковин, каменные скобели. Кроме того, близость к морю со временем позволило обитателям Соноры развивать навигацию, причем, наиболее удачливые и опытные представители народа сери(с) даже достигали острова Сан Эстабан и, возможно, Нижней Калифорнии.

Здесь же, как и в культурах Касас Грандес и Хохокам, очевидно, была известна ритуальная игра в мяч (пелота) месоамериканского происхождения, впрочем, со своими правилами.

Конкретным примером указанных в Соноре процессов является и культура Ла Плайя. На настоящий момент она считается одним из самых известных археологических объектов на Северо-Западе Мексики и Юго-Западе США Раннего земледельческого периода. Ла Плайя располагается в окрестностях реки Магдалена, в Тринчерас на высоте 515 м над уровнем моря и занимает площади около 12 кв км. Большая часть культурных памятников этого археологического объекта открыты в окрестностях горы Сиерра Бокильяс. Кроме традиционных для этих мест находок, а именно, выступающих на поверхности костей ископаемых животных (мамонты, бизоны, верблюды лошади, антилопы, олени, кабаны, черепахи). Здесь встречаются и те, что имеют отношение к культуре поселенцев Ла Плайи. В рамках специального археологического проекта здесь исследовано около
530 археологических объектов, среди которых 283 погребений (250 погребенных и 33 кремированных), 30 погребений собак и 114 очагов. Количество последних свидетельствует об активной хозяйственной деятельности, ее масштабах [5]. В Ла Плайя находят остатки жилищ, большое число орнаментированных морских раковин. Знак того, что их изготовление было значительным по объемам свидетельствуют мастерские, как места, в которых обрабатывались раковины для производства бусинок, серег, браслетов. Собрано также значительное количество наконечников кловис. Следует отметить, что сходные наконечники встречаются на Юго-Западе США.

Обнаруженные предметы и объекты позволили утвердить и определить хронологию Ла Плайи. Археологи предположили, что она развивалась около 10000 лет. Ла Плайя пережила ряд периодов, занимающим в целом хронологический период 12500 г. до н.э. 200 г. н.э. Этот временной отрезок охватывает разные геологические, культурные и исторические периоды (в частности, и то время, когда люди здесь еще не поселились, а хозяевами были ископаемые животные).

В этот период здесь, как и в целом на Северо-Западе Мексики, также происходило изменение климата в виде потепления, сокращения объема осадков.

С постепенным разрушением культуры Ла Плайя, на историко-культурном пространстве Соноры также постепенно начинает формироваться традиция, известная как культура Тринчерас (1300-1450 г.г.).

Тринчерас (Серро де Тринчерас) - это доиспанское поселение и региональный центр такой же важности, культурного и исторического значения в Соноре, как, например, Касас Грандес в штате Чихуахуа. Памятник находится в среднем течении реки Магдалена в северо-западной Соноре.

Основу культуры составляют около 900 террас, которые формируют архитектуру конструкций и архитектонику пространства территории. Открытые археологические памятники были названы археологами «Площадка», «Раковина» и «Наблюдательный пункт» и др.

Земледельческие общины традиции Тринчерас сначала представляли собой небольшие поселения. С этим этапом связана керамика, получившая название «керамика Тринчерас пурпурный по красному» и хронологически относящаяся к 200-800 г.г. В период 800-1300 гг. жители стали строить большие поселения, что свидетельствует о возросших возможно- 
стях для выживания. Как черта погребальной практики, исследователями отмечена замена подземных захоронений кремацией. В период 1300-1450 гг., культура претерпевает еще одну трансформацию. Это доказывается заменой практики изготовления разноцветной керамики монохромной и распространением традиции использования сосудов больших размеров (порой в рост человека), которые использовались для хранения запасов кукурузы (в том числе и после прихода европейцев).

Известное изменение климата с середины $\mathrm{XV}$ в. привело к опустыниванию и, как следствие, стало одной из причин уменьшения населения, снижения количества и размеров поселений. Очевидно, как и в других местах в северо-западной Мексике в целом население вернулось к менее сложной социальной организации, образу жизни и хозяйству.

Культуры древней западной Мексики, а также Аризоны знамениты своими петроглифами. До настоящего времени самые раннее упоминание, которое мы знаем относительно петроглифов на Северо-Западе Мексики, связано с именем иезуита Андрес Переса де Риваса (перв. полов. XVI в.). В XVII в. Якобо Зедельмейер сообщал в своем дневнике, что аборигены покрывали камни и скалы знаками и изображениями фигур. В 1890 Карл Лумхольтц, норвежский путешественник и исследователь, прошедший по территории Соноры, упоминает каменную резьбу, увиденную им в районе поселения Гранадос. В 1909 г., а также позднее он вновь оказался в этих местах и оставил описание петроглифов в окрестностях рек Магдалена, Алтар, Консепсион, Соноито и др. местах. Правда, подлинное описание и изучение петроглифов на Северо-Западе Мексики осуществлялось и позже, вплоть до настоящего времени [6; 11]. Здесь представлены выцарапанные (графрфити), написанные или нарисованные краской (дипинти) изображения. В широком смысле, это то же, что и петроглифы - писаницы, наскальные изображения, выбитые или нанесенные краской изображения на камне. Разница в названиях (в самом общем смысле) связана с тем, что за основу взяты термины на основе итальянского или греческого языка (во втором случае).

По части этих памятников в национальном и международном отношении наиболее известен район полуострова Нижняя Калифорния. Наличие аналогичных культурных проявлений есть и в штатах Чихуахуа и Синалоа.

В настоящее время на территории Соноры известно более двух сотен памятников с петро- глифрами. Некоторые из них имеют считанное число фригур, другие содержат до сотни изображений (рис. 2). Большую часть рисунков и петроглифов можно объединить в группы: антропоморфные изображения, изображения животных, растений (цветов), геометрические фигуры; также встречаются реалистические изображения (правда, весьма редкие).

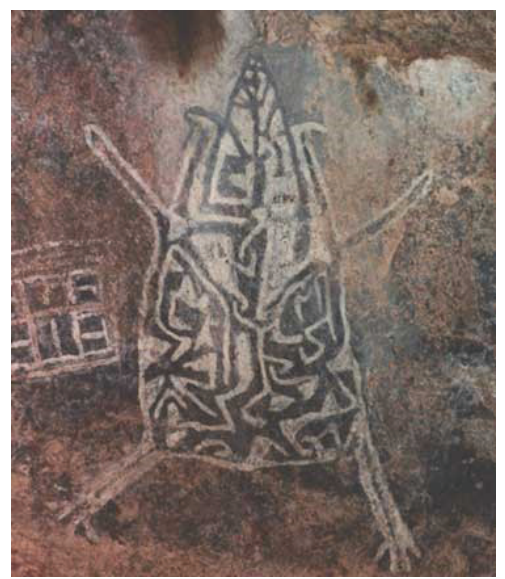

Рис. 2. Петроглиф. Нижняя Калифорни

При изучении петроглифов исследователи отмечают различную технику, стиль исполнения, а также размеры (от нескольких сантиметров до нескольких метров). Различаются они и композиционно: одни фигуры представлены изолированно, другие скомпонованы в виде настоящих картин площадью несколько метров (например, в районе Каборка есть подобный памятник площадью почти десять квадратных метров) [9; 10].

Памятниками, символами и образами, богатством и разнообразием петроглифов в штате Сонора особенно выделяется археологическая зона Ла Пинтада. Красноречив перевод топонима на русский язык - «Граффити». Петроглифы расположены в каньоне того же названия, который составляет часть небольшого горного массива Сиерра Либре в прибрежной равнине Соноры.

Почему эти памятники появились именно здесь? Чтобы понять это необходимо отметить, что их создателями были охотники и собиратели, которые собирали семена дикорастущих растений, ловили рыбу, охотились. Для выживания в условиях пустынной местности им важно было знать места, где находятся водные источники. Как раз в Сиерра Либре находились естественные сборники воды (так называемые, «кадки», «бочки», исп. tinajas): она собиралась в них во время сезонных дождей. 
В каньоне Ла Пинтада на скалах, обрывах и др. можно видеть разные петроглифы. Это, например, изображение персонажа в массивном головном уборе, который держит под уздцы животное; на противоположной стороне изображена птица (в белом цвете). К несчастью, эта часть каньона в наши дни во время дождя постоянно подтапливается. Здесь же находятся объекты, свидетельствующие о местах длительного пребывания указанных групп охотников и собирателей. Отмечается значительная концентрация археологического материала: керамика, каменные орудия, морские раковины и камни, когда-то использовавшиеся для размалывания, растирания зерен.

Большая часть этих археологических материалов описывается учеными как относящаяся к археологической традиции, известной, как культура Центрального побережья. По своим признакам артефакты сходны с находками, сделанными в Тастиота и Пунта Сан Антонио в южной части Центрального побережья. Это показывает, что в доиспанский здесь образовалось некое общее культурное пространство охотников и собирателей.
К настоящему времени исследователями доказано, что наиболее интенсивное заселение района проходило в период 700-1600 г.г., судя по обилию керамики. Это же подтверждает культурную непрерывность, которая позволяет сделать вывод о присутствии здесь носителей традиции Центрального побережья, которыми считаются упоминавшиеся выше сери(с). Подтверждено, что они были единственными поселенцами и, таким образом, петроглифы Ла Пинтады были результатом их деятельности.

Представленный анализ культур древней Соноры показывает как успехи в их исследовании, так и большой круг проблем, задач, которые еще предстоит сделать ученым, прежде всего, археологам Мексики и США. Примечательно, что общей тенденцией современных археологических исследований является внимание к окраинам месоамериканского мира. Хотя ученые осознают, что едва ли следует ожидать сенсационных находок, эфрфектных открытий от этих исследований, однако благодаря им историческая картина и культурная карта дооколониальной Америки станет более ясной и основательной [3].

\section{Источники и литература / References}

1. Баглай В. Е. Традиционные общества древней Западной Мексики: история, археология, этнография тарасков: монография. СПб: Планета музыки, Лань, 2017. 614 с.

Baglay V. E. Traditsionnye obschestva drevney Zapadnoy Meksiki istoriya arheologiya etnografiya taraskov (Traditional societies of ancient Western Mexico: history, archeology, ethnography of Tarascans). St.Petersburg: Planeta muzyki; Lan, 2017. 614 p. (In Russian).

2. Баглай В. Е. Исторический Дуранго: между Месоамерикой и американским Юго-Западом // Латинская Америка. 2018. №8. C.86 - 93.

Baglay V. E. Istoricheskiy Durango mezhdu Mesoamerikoy i amerikanskim Yugo-Zapadom (Historical Durango: between Mesoamerica and the American Southwest) // Latinskaya Amerika. 2018. No.8. P. 86-93. (In Russian).

3. Acosta C.V. Región y cosiedad. Año XXVI. No 59. 2014. P. 215-254. URL: https://www.colson.edu.mx:4433/Revista/ Articulos/59/7Villalobos.pdf (Accessed: 12.09. 2018).

4. Braniff B. C. La historia prehispánica de Sonora // Arqueología Mexicana, indice 97, México. Mayo - junio. 2009. P.1-6. URL: https://arqueologiamexicana.mx/ediciones-regulares/97-las-culturas-de-sonora (Accessed: 18.03. 2018).

5. Carpenter J. S. La Playa, Sonora // Arqueología Mexicana, indice 97, México. Mayo-junio. 2009., P.1-3. URL: http://www. academia.edu/9955307/La_Playa_Sonora._Arqueolog\%C3\%ADa_Mexicana_Vol._XVII_N\%C3\%9AM_97_5053._2009_ (Accessed: 28.04.2017).

6. Contreras B. E. B., Téllez M. G., Garcia D. E. B. La Pintada, Sonora. Voces en el viento, señales en tierra y roca // Arqueología Mexicana. Indice 97. México. Mayo - junio. 2009. P.1-3. URL: https://arqueologiamexicana.mx/mexico-antiguo/ la-pintada-sonora-voces-en-el-viento-senales-en-tierra-y-roca (Accessed: 14.11. 2016).

7. Fish P. R., Fish S. K. La cultura Hohokam del sur de Arisona // Arqueología Mexicana, indice 97, México. Mayo junio. 2009. P. 1-3. URL: https://arqueologiamexicana.mx/mexico-antiguo/la-historia-prehispanica-de-sonora (Accessed: 14.08.2018).

8. Sánchez G. M., Gainez E. P., Vance T. Holidey. El Fin del Mundo, Sonora. Cazadorez clovis de megafauna del Pleistoceno Terminal // Arqueología Mexicana, indice 97, México. Mayo - junio. 2009. P.1-3. URL: https://arqueologiamexicana.mx/ mexico-antiguo/la-historia-prehispanica-de-sonora (Accessed:14.08.2018).

9. Quijada C. A. L. Las investigaciones arqueologicas en Sonora // Actualidades arqueológicas. №22. México. Abril-junio del 2000. P. 1-13. URL: http://www.iia.unam.mx/actualidades/Actualidades/22/texto22/sonora.htmlhttps://arqueologiamexicana. $\mathrm{mx} / \mathrm{mexico}$-antiguo/la-historia-prehispanica-de-sonora (Accessed:17.10.2017).

10. Quijada C. A. L. Las manifestaciones gráfico rupustres en Sonora. // Arqueología Mexicana, indice 97, México. Mayo junio. 2009. P. 1-4. URL: https://arqueologiamexicana.mx/mexico-antiguo/la-historia-prehispanica-de-sonora (Accessed: 21.11.2017).

11. Villapando M. E. Cerro de Trincheras, Sonora. Muros de piedra que acogen la espiral del mar // Arqueología Mexicana, indice 97, México. Mayo - junio. 2009. P. 1-2. URL: https://arqueologiamexicana.mx/mexico-antiguo/la-historia-prehispanicade-sonora (Accessed: 09.12.2017). 